\title{
Pulmonary Inertance
}

National Cancer Institute

\section{Source}

National Cancer Institute. Pulmonary Inertance. NCI Thesaurus. Code C139254.

The measure of the force of the column of air in the conducting airways. 